\title{
Corrigendum: Focused Ultrasound Improves NK-92MI Cells Infiltration Into Tumors
}

\section{OPEN ACCESS}

Approved by:

Frontiers Editorial Office,

Frontiers Media SA,

Switzerland

${ }^{*}$ Correspondence: Zhiyi Chen

winchen@vip.126.com

Fei Yan

fei.yan@siat.ac.cn

Specialty section:

This article was submitted to

Translational Pharmacology,

a section of the journal

Frontiers in Pharmacology

Received: 24 June 2019

Accepted: 10 July 2019

Published: 06 August 2019

Citation:

Yang C, Du M, Yan F and Chen Z

(2019) Corrigendum: Focused

Ultrasound Improves NK-92MI Cells

Infiltration Into Tumors.

Front. Pharmacol. 10:875.

doi: 10.3389/fphar.2019.00875

\begin{abstract}
Chaopin Yang ${ }^{1,2}$, Meng Du ${ }^{1,2}$, Fei Yan ${ }^{3 *}$ and Zhiyi Chen ${ }^{1,2 *}$
${ }^{1}$ Department of Ultrasound Medicine, Laboratory of Ultrasound Molecular Imaging, The Third Affiliated Hospital of Guangzhou Medical University, Guangzhou, China, ${ }^{2}$ Experimental Center, The Liwan Hospital of the Third Affiliated Hospital of Guangzhou Medical University, Guangzhou, China, ${ }^{3}$ Paul C. Lauterbur Research Center for Biomedical Imaging, Institute of Biomedical and Health Engineering, Shenzhen Institutes of Advanced Technology, Chinese Academy of Sciences, Shenzhen, China
\end{abstract}

Keywords: natural killer cells, IL-2, focused ultrasound, microbubbles, ovarian cancer

\section{A Corrigendum on}

Focused Ultrasound Improves NK-92MI Cells Infiltration Into Tumors. Yang C, Du M, Yan F and Chen Z (2019) Front. Pharmacol. 10:326. doi: 10.3389/fphar.2019.00326

In the original article, the name of one author was missed in the reference for "Ponzetta, A., Sciume, G., Benigni, G., Antonangeli, F., Morrone, S., and Santoni, A. (2013). CX3CR1 regulates the maintenance of KLRG1+ NK cells into the bone marrow by promoting their entry into circulation. J. Immunol. 191, 5684-5694. doi: 10.4049/jimmunol.1300090." It should be "Ponzetta, A., Sciume, G., Benigni, G., Antonangeli, F., Morrone, S., Santoni, A., et al. (2013). CX3CR1 regulates the maintenance of KLRG1+ NK cells into the bone marrow by promoting their entry into circulation. J. Immunol. 191, 5684-5694. doi: 10.4049/jimmunol.1300090."

The authors apologize for this error and state that this does not change the scientific conclusions of the article in any way. The original article has been updated.

Copyright ( 2019 Yang, Du, Yan and Chen. This is an open-access article distributed under the terms of the Creative Commons Attribution License (CC BY). The use, distribution or reproduction in other forums is permitted, provided the original author $(s)$ and the copyright owner(s) are credited and that the original publication in this journal is cited, in accordance with accepted academic practice. No use, distribution or reproduction is permitted which does not comply with these terms. 